\title{
MERCI for Improving Quality of Surgical Care at No Cost: Reply
}

\author{
Gaëtan-Romain Joliat ${ }^{1} \cdot$ Martin Hübner $^{1} \cdot$ Markus Schäfer $^{1} \cdot$ Nicolas Demartines $^{1}$
}

Published online: 19 September 2016

(C) Société Internationale de Chirurgie 2016

We thank you for your interest and your comment on our article assessing the implementation costs of an Enhanced Recovery After Surgery (ERAS) program in liver surgery.

Implementation of ERAS programs is similar to other types of projects in the world of business: you have to invest first, and return on investment goes along with the later success if any. For ERAS programs, the return on investment is achieved by improvements in quality of care (diminution of complications and reduction in length of stay) and systematization of management. As you mentioned, the present study illustrates well the benefits of such programs and could serve as prove to convince more hospital managers to implement ERAS programs.

It is true that costs of care are largely varying as reimbursements are mainly depending on the respective health care systems. However, it is not the absolute costs per se that are important but the difference between the costs in a cohort of ERAS patients compared to a cohort of nonERAS patients from a same institution. To this end, it is even secondary whether the observed differences are statistically significant. Several studies showed the cost benefits of ERAS in different countries reinforcing the previous argument [1,2].

At first glance, the MERCI equation seems attractive and simple to use. We agree that prediction with personal and tailored data before investment is of importance. In this

Nicolas Demartines

demartines@chuv.ch

1 Department of Visceral Surgery, University Hospital of Lausanne (CHUV), Rue du Bugnon 46, 1011 Lausanne, Switzerland regard, the MERCI formula is a good suggestion as it may allow a rough guess on cost savings. However, some issues need be considered. The MERCI equation is not referenced and has presently not been externally validated precluding large-scale use. The expected decrease in the complication rate can often not reliably be estimated prior to implementation of an ERAS program. It is based on published data of the literature and often not originating from the same region or country. Even though the Clavien classification allows a standardized reporting of postoperative complications, it does not reference all complications in an individual patient. Currently, more holistic classifications such as the Comprehensive Classification Index could help to correct this issue [3]. Moreover, the MERCI equation does not take into account the durability of cost savings. Indeed, as described in our article, the financial gain is per patient. In consequence, the more patients are treated within an ERAS program, the more savings are done over time.

\section{References}

1. Stowers MDJ, Lemanu DP, Hill AG (2015) Health economics in enhanced recovery after surgery programs. Can J Anaesth 62:219-230

2. Stone AB, Grant MC, Pio Roda $C$ et al (2016) Implementation costs of an enhanced recovery after surgery program in the united states: a financial model and sensitivity analysis based on experiences at a quaternary academic medical center. J Am Coll Surg 222:219-225

3. Slankamenac K, Nederlof N, Pessaux P et al (2014) The comprehensive complication index: a novel and more sensitive endpoint for assessing outcome and reducing sample size in randomized controlled trials. Ann Surg 260:757-763 